\title{
Erratum to: The human dimensions of water saving irrigation: lessons learned from Chinese smallholder farmers
}

\author{
Morey Burnham · Zhao Ma • Delan Zhu
}

Published online: 13 January 2015

(C) Springer Science+Business Media Dordrecht 2015

\section{Erratum to: Agric Hum Values \\ DOI 10.1007/s10460-014-9565-8}

Due to an unfortunate turn of events wrong units have been introduced in two instances. One under the heading "Conflict and cooperation" where it should read:
"In both villages, each household had an average of 12-15 mu ( 2-2.5 acres) of land divided across three to four plots."

The other in Table 2 (reproduced in this erratum) where the column title should read "Total land (mu)". Both should be regarded as final version by the reader.

The online version of the original article can be found under doi:10.1007/s10460-014-9565-8.

M. Burnham

Department of Environmental Studies, College of Environmental Science and Forestry, State University of New York, 1 Forestry Dr., Syracuse, NY 13210, USA

e-mail: moreyburnham@gmail.com

Z. Ma ( $\square)$

Department of Forestry and Natural Resources, Purdue

University, 195 Marsteller Street, West Lafayette,

IN 47907-2033, USA

e-mail: zhaoma@purdue.edu

D. Zhu

Agricultural Water and Soil Engineering Laboratory, Northwest

Agriculture and Forestry University, 23 Huiwei Road,

Yangling 712100, Shaanxi, China

e-mail: dlzhu@126.com 


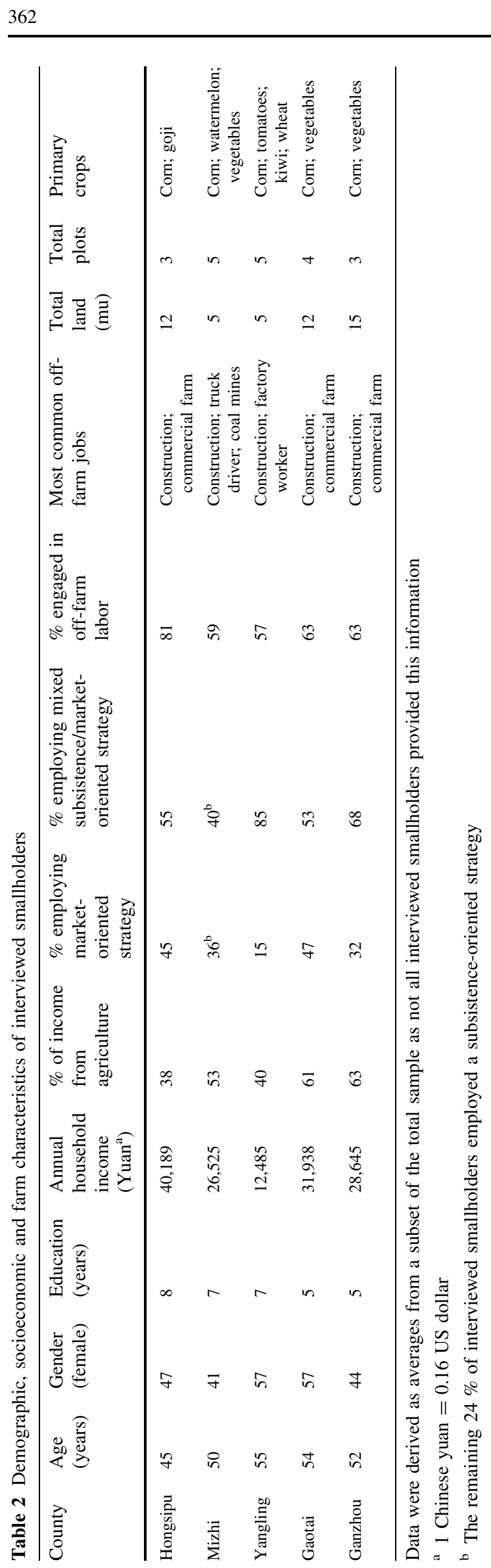

Springer 